\title{
Selecting Features Of A Web Platform To Enhance Course Delivery
}

Karen A. Berger, (E-mail: kberger@pace.edu), Pace University, Pleasantville Martin T. Topol, (E-mail: mtopol@pace.edu), Pace University, New York

\begin{abstract}
This paper reviews key features of popular Web platforms used for course delivery. Institutions of higher education have rushed to adopt these platforms for several reasons. From the point of view of the educator, the most important reason is to enhance the classroom experience (real or virtual). "Classroom" experiences can benefit from a continuous stream of discourse made possible by the communications tools available in the web platforms designed for educational application. In addition, web platforms can serve as a means of collecting and distributing content from various sources - including all class participants. A review of studies from current business education literature conducted to assess the pedagogical impact of the use of some of these features is included. The authors' also provide excerpts from their pages and classroom experiences in a traditional classroom and in distance learning with asynchronous communication, including email and bulletin boards, synchronous communication, content creation that includes course outlines and handouts, online surveys and exams and the digital dropbox. Platforms which are reviewed include Blackboard v. 5.5, WebCT v. 3.0 and WebBoard v. 4.0.
\end{abstract}

\section{Introduction}

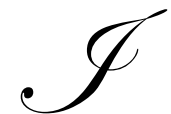

nstitutions of higher learning all over the world are incorporating Web-based teaching and learning products, such as Blackboard and WebCT, as news of their use has spread. Marketers of these products claim that the use of their platform will "add a new level of excitement to learning", "excite your students and facilitate idea sharing" and "challenge your students" (blackboard.com, 7/20/01). Schools are choosing to use these products in the hope that they will help to improve the quality of learning, make the information and professor more accessible to students and create greater student satisfaction and improve enrollments. Other institutions are adding these products as a vehicle for distance education hoping to balance financial demands and student needs.

From the point of view of the educator, the most important reason to adopt any new method is to enhance the classroom experience whether it is real or virtual. Secondarily, an innovation which will simplify the tasks of the professor is likely to be a popular change as well. For those making the decision to use a Web platform for their courses, this paper will review the features available providing a combination of research information and personal classroom experience to assist the new user in the preparation process. A review of studies from current business education literature assessing some of these tools will also be included.

Web site platforms refer to an integrated suite of software tools that is generally designed by a third party, not the institution. The 'platform' provides a means of collecting and distributing all instructional materials and incorporates administrative tools relevant to their classes. These platforms are generally viewed as preferable to building/developing a Web site, since this approach provides users with the ability to place courses online with relative ease and little or no knowledge of programming. Professors can thus concentrate on content, rather than technology and programming. From the point of view of the institution, the use of a platform allows its course Web

Readers with comments or questions are encouraged to contact the authors via email.

sites to have a uniform level of quality and continuity consistent with the image and focus of the institution. The 
common elements of the platform can help create a community of teachers and learners with administrators maintaining the "look" of the platform and its portals and back-end integration (Berger and Topol 2001)

The publishing industry is fueling the interest in Web platforms or electronic learning platforms as they are sometimes called. These platforms have "inserted a whole new computerized layer into the academic process..." (Lichtenberg 2001, p. 40). This, in turn, makes it easy for publishers to provide varying levels of content. For example, the newest generation of WebCT provides a course management system which provides 'e-packs' or materials which include customizable online course content, including video animations, sample syllabi, lecture notes, quiz and test banks, and glossaries packaged with course management software. Other e-content providers are introducing their versions of the WebCT product package (Lichtenberg 2001).

Four platforms are compared here in terms of the features that are available (see Table 1). The platforms that are reviewed include Blackboard v. 5.5, WebCT v. 3.0 and WebBoard v. 4.0. Several features are common to most of these platforms. First, this paper will discuss some of the pedagogical objectives that a professor might have. Then, the paper will discuss the features available and how these features can be used to enhance course delivery in a traditional course or in an online course. Importantly, the purpose of this paper is to focus efforts on the development of quality enhancement to teaching and learning environments.

\section{Pedagogical Objectives}

Much of the literature on learning in marketing education deals with the need for skill development and enhancement in the curriculum (see, for example, Lamb et al. 1995; Chonko 1993). This reflects the interest of professors to teach students how to think about issues critically. However, this has proven to be a difficult enterprise in spite of the number of faculty who have restructured their courses to facilitate critical thinking. Traditional lecture is being replaced with discussion. The consensus of experts seems to be that professors are working harder to promote critical thinking as well as communication skill growth (Smart, Kelley and Conant 1999).

Most recently, authentic learning has received much attention with professors trying to improve the "imprint" of our teaching through real world experience (Lafer 1997). The consensus of opinion is that institutions of higher learning want their graduates to become lifelong learners with the ability to think critically and to make decisions in their work and daily lives, but that changes must continue to be made in the classroom experience so that the learning that occurs improves graduates' competencies (Smart, Kelley and Conant 1999).

The dialog of how professors and teachers can improve the larger educational experience has been extended as new technology has created new ways to reach and communicate with our students. Some believe that this new technology can be used to not only amplify current classroom practices, but to help make "radical changes in the work of teachers and the learning of students" (Girod and Cavanaugh 2001). Their thesis is that doing more of the same in a better way with technology does not capitalize on the full potential and power of most technology resources. As such, faculty are challenged to utilize technology and Web access in the classroom in a way that creates a new, revitalized learning experience for students. The prospect and promise, of web platforms and other instructional software tools is especially positive, but the task can be daunting. Professors and teachers must develop ways to maximize the potential of the new technologies. To do so requires a commitment to upgrade one's own skills and expertise in the use and application of technology apart from whatever upgrade may be required in one's own knowledge of the discipline(s) they may teach.

This paper will take several features common to the most commonly advertised and used Web platforms and discuss them in terms of their pedagogical potential. In some cases, teaching experiences of others will be cited; in other cases, the authors' experience and suggestions for the use of the feature will be discussed.

\section{Web Platform Features}




\section{Content Creation}

The traditional way to begin a course is to distribute a hard copy of the syllabus. Many instructors have come to see this document as a contract with the students for what the professor will do and, in turn, what the student must do in order to complete the course successfully. A course Web site allows the professor to easily post many types of materials, including the course syllabus. Unlike a hard copy, the syllabus can be updated regularly. Using other Web-based features, the professor can post a note to students letting them know that the syllabus has been modified. Blackboard and WebCT have an 'Announcement' feature at the portal page that increases the likelihood of students' reading the message. WebBoard has an asynchronous communication which allows a professor to post a message to the entire community, but does not have an 'Announcement' section.

For professors using Web sites as enrichment material for the course, being able to incorporate links to other parts of the Web can be invaluable. Blackboard and WebCT allow the user to cut and paste documents from various web sites (assuming this is permitted by the copyright holder) and put them directly on the Course Web site. This method allows students to go directly to Course Web site and read the material on line. The student does not have to have special software to read the material which they can print out page by page.

If the professor has a lot of material or if the material appears on a Web site, it may be easier to just incorporate a link which students can click on to access the material. This may be required when the web site invokes the copyright it holds. Of course, there is always the possibility that the Web site will change (and thereby invalidate the link) or that the students do not have the appropriate software or passwords to access the file. Some sites require registration prior to use so that students who do not register will not gain access to the desired pages. Cookies are generally used to ease navigation within a site, but may also be used to control access to a site or portions of a site. As such, the absence of a cookie, which is obtained upon registration with the site, may produce problems for students attempting to follow a link to a site. Such problems can result in a classroom filled with frustrated students who were unable to complete their assignment.

Depending on the platform, there can be problems downloading the files residing on the site or problems with the platform itself. One of these problems is the difficulty that occurs when there are differences in the versions of software used by the student versus the professor. For example, if a professor posts a PowerPoint file which has been saved as HTML and zipped, the student may have some difficulty downloading the file if it was created and saved as a PowerPoint 2000 file rather than an earlier verison of PowerPoint. Further problems may occur without "WinZip" to unzip the file. One way this can be overcome is to post an "HTML" version and a PowerPoint file. Printing a PowerPoint file is faster, but providing the "HTML" version ensures that all students will be able to access the notes. While this requires a bit more work, it is often worth the effort.

Compared to collecting, reproducing and distributing "hard-copies" of materials to students in class, the ease of adding web-based material via a Web platform allows the professor to provide access to a greater wealth of resources than ever before. Importantly, web platform tools allows the professor to provide more guidance to the students for reading, analyzing and integrating the various course materials. Students who might want to engage in greater study or need to know more can be provided additional references and links to other Internet sites. As such, students can find what they need to know in a variety of ways. Note that the use of the linking features of a Web site means that the order of the information may be accessed and conveyed differently from student to student. Nonetheless, the student can access material in his or her own way on his or her own time, and may do so from any browser. As such, the professor can offer a great deal more supplementary content to the student beyond the limitations of class time, or for that matter the limitations of many libraries' physical collections.

The pedagogical consequences of using this approach are significant. First, the role of the professor may grow from 'information resource' and 'content provider' to a facilitator and coach who enables student discovery. Second, the faculty member's historical role of keeper and disseminator of information is de-emphasized (Kaynama and Keesling 2000). Indeed, the traditional classroom format puts the teacher in the role of 'keeper of the subject matter,' the one who defines the learning contexts for the students. When one moves to the use of a Web platform, 
the view of the learning community can be extended beyond the confines of a traditional classroom and can link both traditional students and remote locations and/or virtual learning environments. As such, the contextual boundaries and geophysical properties of a classroom may be challenged through further hyperlinking and interactivity beyond postings on bulletin boards, via chatting in virtual communities which can be local, regional, national or global (Girod and Cavanaugh 2001).

\section{Asynchronous Communication}

The asynchronous communication features of a Web platform allow on-line conferencing to occur between students and faculty and between students. In addition, these platforms allow faculty to form groups that can have their own bulletin board area. There are some differences between platforms, so it is suggested that professors review this feature carefully to ensure that it meets the pedagogical needs of the course or assignments. In a case class, the professor can set up separate spaces for each case, so that group members can post their work-in-progress. This can be quite helpful to provide work which can be evaluated if a dispute occurs in the group. While the dialog that occurs is asynchronous (like e-mail, not occurring in real-time), this method of communication actually serves to increase out-of-class discussion between faculty and students (Berger and Meyer 1999). For groups, this feature stimulates collaboration following closely upon the corporate use of collaborative tools and workforce software (Agnew 2000). As such, students develop skill in collaboration that may prove valuable upon entry into the workforce.

The term, bulletin board, is used to describe the space in which the asynchronous communication is placed or posted. This tool permits students to reply to or solicit the comments of their peers or instructor. By and large, the freedom to comment on each other's ideas is relatively unconstrained - that is, no one must wait to be recognized in class for permission to speak. Here, the faculty member does not have to manage the length of discourse bound by the constraint of class time. Rather, the faculty member becomes a moderator attempting to observe and participate when probing is necessary. Still, some controls may be useful, and web platforms allow instructors to govern access to specific areas of the course web site giving permission to post to specific areas - as deemed appropriate by the instructor. It is fairly common to find a growing stream of questions, answers and comments once students become adept at using the asynchronous communications tools. What emerges is called a threaded conversation. When used properly, this approach can create a "democratic" classroom, quite different from the traditional approach to teaching. In a strictly on-line classroom, these threaded conversations can be more thorough and at a higher level of critical thinking than might be possible in a regular classroom. As such, the threaded conversation can be directed by the professor (by initiating probing/thought questions for discussion), and by jumping in to add comments to focus the on-line discussion. Pressing students to think, evaluate, reason and argue, the faculty can orchestrate the learning process in a fashion that is quite probably uncharacteristic of the "traditional" classroom discussion. In fact, a summary of the threads of the conversation for the week can be posted by the professor to help the students follow all the trains of thought and "discoveries" (Ryan et al. 2001).

Especially useful in a marketing class is the feature of on-line conferencing that allows the faculty member and students to post links for sites that students have found on the Web. For instance, students can search the Web for sites which illustrate marketing concepts discussed in class or a new e-commerce site with a seemingly innovative business model; easily accessed with a click, the faculty member can retrieve, review and respond to the site, all directly from the bulletin board. Later in class, the course Web site can be accessed and student work can be easily shown during the class facilitating in-class discussion. If the class is a distance learning class, the discussion can occur in a bulletin board space specially designated for that topic.

The bulletin board is also a useful tool to encourage critical thinking: Knowledge, Comprehension, Application, Analysis, Synthesis, and Evaluation (Bloom et al. 1956). Using the bulletin board and its postings to assignments, students can be encouraged to think more deeply and thoroughly about a subject. The faculty member must respond on a timely basis to postings, so that students have time to respond, hopefully, in a more thoughtful manner. Using Bloom's taxonomy, students can be moved from a state of knowledge of previously learned material to application, or using concepts and principles in new situations to "solve" the problem or answer the questions. For example, if students have learned about the concept of personalization on the Web, this knowledge can be used to find 
a site, like Amazon, which uses this approach. This demonstrates comprehension of the concept. However, if a student looks at a different site and shows how personalization can be used there to improve customer service, then the student has taken his knowledge and applied it to a separate, new situation, moving to the application level. The better undergraduate students and graduate students can move to level four, or analysis, looking at a site and separating the advertising "hype" or puffery from the factual information, and drawing conclusions about the strengths and weaknesses of the site and perhaps the effective use of personalization. Consequently, the concept of personalization may become part of the analysis of a business model. Taken to a higher level, students may be able to engage in synthesis and evaluation (Berger and Meyer 1999).

Another taxonomy of critical thinking has been used in a Management case context by Mingers (2000). He defines critical thinking as the process of questioning or evaluating claims before deciding or acting. His approach involves having students evaluate the implicit assumptions of a case situation or description. While the author did not write about the use of technology, the design of this course and its objectives lend itself nicely to adaptation to an asynchronous bulletin board.

Networking skills can also be developed with students getting to "know" each other on-line, while they might not have otherwise. However, with some students, exercises may be required to obtain this result. Group projects which require that students read and comment on other student postings can be helpful, especially when there are a large number on non-resident/commuter students who have little time to stay around school or after class.

The skills for negotiation can be worked into a bulletin board exercise as well. Students, for example, may be encouraged to "prove" to their classmate(s) that the sites they have selected, or the position they have taken regarding a site, is best for the situation. This can then lead to a dialog in which one student "negotiates" with another. The process of negotiation has been recognized by industry as important. Wall Street Journal columnist Hal Lancaster has been known to say that "Life is a negotiation" and Chester Karrass, author of The Negotiation Game, has made famous the slogan, "You don't get what you deserve, you get what you negotiate." In international business, the process of negotiation has been recognized as important for bringing conflicting parties into agreement. As international business grows in scope, these skills are likely to become increasingly important (Edson 2000). A bulletin board can be used to foster these skills by giving students a chance to disagree in a principled way in a nonpersonal context. Tact and diplomacy are developed over time and students are quick to respond to peers who are insensitive, cavalier and flagrantly disregard social conventions.

Writing skills can also be enhanced through asynchronous, bulletin board communication. The authors encourage students to write and assure them that there will be no reprisal for mistakes. Since there is no 'spell check' or 'grammar check' on the bulletin board, students who have serious problems are advised to type their answers in a word-processing program and then "cut and paste" them into the bulletin board. In sum, they are given a writing opportunity, but are asked to always be aware of spelling and grammar. For grading purposes, this exercise emphasizes the practical and substantive content. Style should not be thoroughly discounted for students, and they should always be reminded of the importance of language mechanics. This is especially true in classes filled with students who are not native speakers of English.

Significant differences in the communications skills and reactions to distance learning and on-line conferencing have been observed in students drawn from diverse language backgrounds and cultures. For these students, distance learning and on-line conferencing are perceived as burdensome. The authors have found that the use of the telephone and face-to-face communication may become necessary in some instances. Still, some foreign students have commented that they view the asynchronous environment advantageous since they are able to labor over their postings, so that they can avoid the embarrassment they fear may come when "speaking up" in class. Again, cultural differences also factor into students' willingness to actively participate in class. Under these circumstances, the bulletin board format is actually preferred because of its private and somewhat controlled nature.

In fact, the quality of the work of these students may actually be enhanced. Hilton and Kameda (1999) corroborate this with their study where Japanese and American students were put together in pairs to share their evaluations of an international business scenario. The Japanese students had to write in English, obviously not their native 
language. Through this project, they obtained good practice outside of their native language and found that e-mail was a "congenial medium because they produced a substantial amount of relatively complex correspondence." The authors concluded that "...students feel safer using e-mail than talking in person, and are more willing to take linguistic chances over the Internet than when speaking or writing formally." Had a bulletin board been deployed instead of traditional email, all messaging could have been posted in one location, making it easier to follow the threads of the discussion. A web platform may have facilitated better evaluations (the students' assignment) but may have been perceived to be a bit more threatening given that many more classmates would be privy to their individual postings.

Importantly, bulletin board postings are authentic, supporting proponents who say that students need to be given authentic experiences, i.e. those which are not just crafted for the teacher's perusal and evaluation. Thus, a bulletin board provides a way of achieving this. Here, students can practice writing as a means of speaking and discussing real world issues with their classmates. The authors regularly give students assignments calling for a review of actual Web sites that they are interested in (as consumers). By posting to the class the bulletin board students are provided a tool that facilitates sharing thoughts, ideas, and critiques with the classroom "community." Left on their own students typically select web sites with which they are more highly involved. As such, faculty must encourage students to explore new sites and use the bulletin board medium creatively to obtain its maximum value. To accomplish this may require asking students to illustrate the diversity of web design and its discontinuities.

Rea, Hoger and Rooney (1999) suggest that business communication can be taught using technology in situations where the technology is not the focus of the course, but rather a means to an end. Specially, they recommend that teachers need to give students the tools to " learn the general principle(s) of (the) application rather than the specifics of individual software - which can be obsolete before it is installed. They further suggest that students be taught to use the applications effectively in the context of business communication, rather than learning the intricacies of the software and systems that support them. The authors have used this approach in an Internet Marketing course in which students have been taught some basic HTML and have been asked to use this material to develop a strategically sound and logical analysis of an existing Web site. While some class time has been given to review HTML, students are expected to work with the language on their own. Given the "marketing" focus of the course HTML is expected to be used only to help communicate what the site is about with more emphasis on the analysis and less on the intricacies of the programming.

When comparing bulletin boards to e-mail, the most evident difference is the degree of privacy. E-mail is, for the most part, an activity involving two or more parties exchanging messages. A posting on a bulletin board is essentially an e-mail that is intended for all participating in the discussion. However, it may be useful and sometimes necessary to respond to open postings with e-mail, if privacy is needed. If the professor does not want to embarrass a student about their individual work (e.g., quality or timeliness) or some other personal matter, the professor can send an e-mail directly from the bulletin board, saving time and maintaining the integrity of the student-faculty relationship. Web platforms facilitate several alternative means of one-to-one and one-to-many communication.

\section{Messaging System}

The latest versions of Blackboard and WebCT have messaging systems where students and faculty can be alerted to the others' presence on line. In this way, synchronous communication can take place when it is convenient for both parties. This is a feature that can be useful if a faculty member is willing to keep their course Web site open while working; but can be quite distracting if the faculty member is trying to complete other work. This points out the advantages of asynchronous communication. Each party has the opportunity to send his or her communication at a time that is convenient for him or her. Students often write into the early hours of the morning; some professors write their messages at that time, but others prefer the early morning. Many different work-styles and habits can be accommodated.

\section{Synchronous Communication - Real-time Chat}

Very little has been written about the use of synchronous communication in higher education, but its use 
has increased steadily in recent years as Web platforms which offer this feature have been adopted for use by institutions of higher learning. Synchronous communication refers to communication between parties that occurs in "realtime", i.e. both parties are on the computer at the same time. IRC, formally known as Internet Relay Chat, is the most prevalent form of synchronous communication. One user types a message in real time to one or more Internet users. Almost instantaneously, the message appears on the monitors of all the other users who are "in" the chat room or area. The other users can respond to the message so that the first sender and others in the chat room can see. These electronic interchanges or "conversations" can be purely social or can involve the exchange of scientific, technical or other information (Simpson 2000).

The potential of this feature is enormous. No longer does information exchange, common to a traditional classroom, have to occur in a physical classroom space. The teacher can be in one geographical location and the students can be in other areas as well. The downside is that for most users, the programs that are widely available offer no video capability; communication is restricted to the text input of the participants. However, this technique can allow individuals from distance locations to discuss plans, projects, theories, and ideas, at a low cost. The individuals involved in the interchange can be teachers collaborating in a workshop, students working with students from far away, or teachers and students in different locations. The teachers can be classroom teachers given the assignment to run the class or noted authors, scientists or guest speakers (Simpson 2000).

IRC transforms the computer into a device which can link people from all over the world. The nursing profession has used this medium to share communication with health care professionals using a variety of nurse chat sites using both open and private channels, depending upon the type of communication. Nursing instructors may create channels for their clinical groups, so that they can keep in touch with them while they are out in the field. Entire classes have been taught using IRC groups, including the use of real-time examinations and instructional graphic files. IRC has even facilitated in-service training to groups of nurses, some of them critical care nurses, around the world. In this case, IRC provides a medium for sharing case studies online (Russell 2000).

Most Web platforms provide user access to both synchronous and asynchronous features which can be incorporated in one's courses. The use of both these features can have synergistic effects in which the students profit greatly from their use together. The asynchronous features allow the student the flexibility to work whenever he or she can; the synchronous feature allows the student to ask questions during an on-line "office hour". The University of Texas has incorporated this approach in its Telecampus program in which freshman are able to take some of their courses on-line. These courses offer the students on-line lectures, homework assignments, chat room office hours and other features as well (Times - Picayune 1999).

\section{Synchronous Communication - Whiteboard lectures}

This synchronous feature offers the user space to provide students with a white board space onto which the instructor can write notes as one would ordinarily do in a physical classroom site. With this feature, the professor can enter text, draw arrows and diagrams or just draw in free form. The white board can be used in conjunction with IRC or, with add-ons, streaming live audio and video presentations.

The standard platforms, such as Blackboard and WebCT, are compatible with streaming video and audio; thus, if an institution has the software and/or server to deliver these features, the Web platform can be used to deliver a presentation that is enhanced by Whiteboard.

Horizon Live is the name of one such software system which offers a synchronous approach to distance education. By comparison, Blackboard, WebBoard or WebCT are mostly asynchronous tools with a very primitive set of real-time features. The HorizonLive software allows presenters to deliver both audio and video presentations and produces a full archive of the event, so that participants who were unable to make it to the real-time event can view the lecture at their convenience. The interface can be customized to enlarge the video screen or other windows, to eliminate windows or add windows as needed (www.horizonlive.com/products). This product is especially useful in cases where the students are geographically dispersed and are unable to meet with the professor during the course. 
The quality of the images is excellent and the students are able to respond with IRC, bringing together all the communications elements. Organizations have readily adopted this software/service provider, because it allows them the flexibility to hire expert guest speakers who find this approach attractive given that travel is not necessary (Eisinger 2000). With unlimited scalability, HorizonLive allows users to $\log$ on to a real-time presentation, view video feeds, listen to streaming audio and interact with the speaker by asking questions either by voice or in writing.

Some additional equipment may be needed, such as a microphone or RealNetworks or HearMe software (HorizonLive.com, 8/13/01).

\section{Course Web Site Statistics}

Web platforms also offer features which can greatly facilitate the tasks of the instructor. Course Web site statistics is one such feature providing information about usage of the site by students or participants. Each Web platform is different slightly in terms of the information available in its statistical reports. For example, Blackboard provides an overall summary of usage, reports for main content areas, communication areas, group areas and student areas. In addition, reporting information on the total number of accesses per area, the number of accesses over time, accesses per hour of the day, accesses per day of the week and accesses by user (Blackboard customer service call June, 2001). On the other hand, WebBoard provides significantly more limited information offering only statistics on the top ten overall users, including number of logins, postings and message contributions (O'Reilly Associates, customer service call June,2001). Third-party software, such as WebTrends, an e-business product line from NetIQ, can be used in conjunction with WebBoard to retrieve additional usage statistics. This company offers a variety of solutions for Web analytics and Visitor Relationship Management (NetIQ Web site).

\section{On-line File Exchange, On-line grading}

Some Web platforms offer on-line file exchange, on-line testing and on-line grading. While it is not necessary to use these features, they can greatly facilitate the job of the professor in managing a course. On-line file exchange provides the professor with the ability to accept papers from students and to return them via the platform (without exiting and using an e-mail program). On-line testing allows the professor to give a test to a student while on-line. In a traditional course, the professor can give the test in an electronic classroom with each of the students seated in the class. The platform will grade each exam and will provide statistics for the professor on the grades, means and other data. These data can be used in the on-line grade book to calculate final grades with ease. These programs are not perfect, however. For example, giving activities different weights can be a problem and may be more easily done with an Excel spreadsheet. Files from the platform can be imported into Excel if necessary.

\section{Conclusions}

The markets for e-learning approaches, software and equipment have grown dramatically and are expected to continue to grow as multimedia and communication technologies continue to improve over time (Lau 2000). While the issues of which technology is best will continue, educators must work to develop new techniques and teaching methodologies which demonstrably improve the quality of learning and education. With the continued decline of incoming students in business, professors will need to justify their place on the faculty. This technology has put pressures on professors to increase experiential learning assignments and activities utilizing the new technologies wherever possible. Given the rise in expectations of employers of their new hires' skills in problem solving and communication, professors must also continually evaluate the new techniques and approaches in terms of effectiveness and satisfaction in these and other skill areas.

\section{References}

1. Agnew (2000), "Collaboration on the Desktop - Web conferencing and instant messaging bring people together", Information Week, July 19, p. 87. 
2. Berger, Karen A. and Jeanine Meyer (1999), "On-line Conferencing in a Marketing Course: Description, Analysis and Reflection", Proceedings of the $9^{\text {th }}$ World Marketing Congress, Academy of Marketing Science, Qawra, Malta, June 23-26.

3. Berger, Karen A. and Martin T. Topol, "Technology to Enhance Learning: Use of a Web Site Platform in Traditional Classes and Distance Learning", pending publication, Marketing Education Review.

4. Blackboard.com, 7/20/01.

5. Blackboard.com, Customer service call, 6/15/01.

6. Bloom, Benjamin S. et al. (1956), Taxonomy of Educational Objectives: The Classification of Educational Goals, New York: Longman Inc.

7. Chonko, Lawrence B. (1993), "Business School Education: Some Thoughts and Recommendations". Marketing Education Review, 3 (1): 1-9.

8. $\quad$ Edson, Lee (2000), "The Negotiation Industry", Across the Board, April 14-20.

9. Girod, Mark and Shane Cavanaugh (2001), "Technology as an Agent of Change in Teacher Practice", T.H.E. Journal, April.

10. HorizonLive.com/products, 8/13/01.

11. Hilton, Chad and Naoki Kameda (1999), "E-mail and the Internet as International business communication teaching and research tools - a case study", Journal of Education for Business, 74(Jan./Feb.), pp. 181185 .

12. Kaynama, Shohreh A. and Garland Keesling (2000), "Development of a Web-based Internet marketing course", Journal of Marketing Education, 22 (August), pp. 84-89.

13. Lafer, Stephen (1999), "Audience, Elegance and Learning via the Internet", Computers in the Schools, v. 13, n. 1-2, 89-97.

14. Lamb Jr., Charles W., Shannon Shipp, and William Moncrief III (1995). "Integrating Skills and Content Knowledge in the Marketing Curriculum", Journal of Marketing Education, Summer.

15. Lau, R.S.M. (2000), "Issues and Outlook of e-Learning", South Dakota Business Review, December, Vol. LIX, No. II.

16. Lichtenberg, James (2001), "Going the Distance", Publishers Weekly, June 25, 37-40.

17. Milone, Michael N. (1997), "Virtual Learning Gets Real”, Technology and Learning, February 17 (Feb.), 15.

18. Mingers, John (2000), "What is it to be Critical? Teaching a Critical Approach to Management Undergraduates", Management Learning, Vol. 31(2): 219-237.

19. NetIQ.com, Web site for business management infrastructure solutions software, 8/21/01.

20. Oreilly.com, Web site for marketer of WebBoard, 6/20/01.

21. Rea, Alan, Jr., Beth Hoger, and Pam Rooney (1999), "Communication and Technology: Building Bridges Across the Chasm", Business Communication Quarterly, June, 62:2, 92-96.

22. Russell, Edward L. (2000), "Internet Relay and Web-based Chat: Powerful Tools for Teaching and Collegial Networking", Critical Care Nurse, Vol. 20, No. 4, August 74-77.

23. Rodes, Paul, Dennis Knapczyk, Carrie Chapman, and Chung Haejin (2000), "Involving Teachers in WebBased Professional Development”, $T$ H E Journal, 27 (May), p. 94.

24. Ryan, Joseph, Mary Jo Prezioso and Beth Gordon Klingner (2001), "From All Sides: faculty members, a student and an administrator discuss on-line courses managed in Blackboard", presentation at the Teaching, Learning and Technology Roundtable Conference, May 18.

25. Simpson, Carol (2000), "Internet Relay Chat", Teacher Librarian, Vol. 28, No. 1, October, 18-20.

26. Smart, Denise T., Craig A. Kelley and Jeffrey S. Conant (1999), "Marketing Education in the Year 2000: Changes Observed and Challenges Anticipated", Journal of Marketing Education, (December), Vol. 2, No. 3, pp. 206-216.

27. Times - Picayune, New Orleans (1999) "University of Texas System Offers First-year Courses on the Internet", August 18.

28. Young, Jeffrey R. (1997). "Rethinking the role of the professor in an age of high-tech tools". The_Chronicle of Higher Education, Oct. 3.

Table 1:

Web Platform Evaluative Criteria 


\begin{tabular}{|c|c|c|c|c|}
\hline & $\begin{array}{l}\text { Course-Info } \\
\text { v. } 3\end{array}$ & $\begin{array}{l}\text { BlackBoard } \\
\text { v. } 5\end{array}$ & $\begin{array}{r}\text { WebCT } \\
\text { v.3.5 }\end{array}$ & $\begin{array}{l}\text { WebBoard } \\
\quad \text { v. } 4\end{array}$ \\
\hline $\begin{array}{l}\text { Asynchronous communication } \\
\text { (e.g., threaded discussion) }\end{array}$ & $\mathrm{Y}$ & $\mathrm{Y}$ & $\mathrm{Y}$ & $\mathrm{Y}$ \\
\hline E-mail & $\mathrm{Y}$ & $\mathrm{Y}$ & $\mathrm{Y}$ & $\mathrm{Y}$ \\
\hline $\begin{array}{l}\text { Synchronous communication } \\
\text { (e.g., real-time chat) }\end{array}$ & $\mathrm{Y}$ & $\mathrm{Y}$ & $\mathrm{Y}$ & $\mathrm{Y}$ \\
\hline $\begin{array}{l}\text { Presentation of live "White } \\
\text { board" lecture notes }\end{array}$ & $\mathrm{Y}$ & $\mathrm{Y}$ & $\mathrm{Y}$ & $\mathrm{N}$ \\
\hline $\begin{array}{l}\text { Assessment tools (e.g., } \\
\text { surveys, quizzes) }\end{array}$ & $\mathrm{Y}$ & $\mathrm{Y}$ & $\mathrm{Y}$ & $\mathrm{N}$ \\
\hline On-line grade book & $\mathrm{Y}$ & $\mathrm{Y}$ & $\mathrm{Y}$ & $\mathrm{Y}$ \\
\hline $\begin{array}{l}\text { Platform access - frequency, } \\
\text { number of users, use by } \\
\text { topic/area }\end{array}$ & $\mathrm{Y}$ & $\mathrm{Y}$ & $\mathrm{Y}$ & $\mathrm{Y}$ \\
\hline $\begin{array}{l}\text { Creation and tracking of student } \\
\text { "user" groups, teams, etc. }\end{array}$ & $\mathrm{Y}$ & $\mathrm{Y}$ & $\mathrm{Y}$ & $\mathrm{N}$ \\
\hline $\begin{array}{l}\text { Content creation and design } \\
\text { (e.g., syllabi, course materials, } \\
\text { cases, notes, ... handouts). }\end{array}$ & $\mathrm{Y}$ & $\mathrm{Y}$ & $\mathrm{Y}$ & $*$ as attachment only \\
\hline Instant Messaging & $\mathrm{N}$ & $\mathrm{Y}$ & $\mathrm{Y}$ & $\mathrm{N}$ \\
\hline $\begin{array}{l}\text { On-line file exchange } \\
\text { (e.g., digital dropbox) }\end{array}$ & $\mathrm{Y}$ & $\mathrm{Y}$ & $\mathrm{Y}$ & $\mathrm{N}$ \\
\hline $\begin{array}{l}\text { On-line tutorial (instructional } \\
\text { help for use of the } \mathrm{Web} \\
\text { delivery tools) }\end{array}$ & $\mathrm{Y}$ & $\mathrm{Y}$ & $\mathrm{Y}$ & $\mathrm{Y}$ \\
\hline Database integration & $\mathrm{Y}$ & $\mathrm{Y}$ & $\mathrm{Y}$ & $\mathrm{N}$ \\
\hline Virtual video-streaming & $\begin{array}{l}* \text { indirectly } \\
\text { compatible }\end{array}$ & $\begin{array}{l}* \text { indirectly } \\
\text { compatible }\end{array}$ & $\begin{array}{l}* \text { indirectly } \\
\text { compatible }\end{array}$ & $\mathrm{N}$ \\
\hline Scalability & $\mathrm{Y}$ & $\bar{Y}$ & $\bar{Y}$ & $\mathrm{~N}$ \\
\hline $\begin{array}{l}\text { KEY: } \\
Y=Y e s \\
N=\text { No } \\
\mathbf{a}=\text { Limited statistics are availa }\end{array}$ & garding & & & ere) \\
\hline
\end{tabular}

